\title{
EDUCAÇÃO AMBIENTAL NA EDUCAÇÃO INFANTIL
}

\author{
https://dx.doi.org/10.48097/2674-8673.2021n5p07
}

\author{
Rafaela do Nascimento Rocha ${ }^{1}$ \\ Sílvia Cavalcanti ${ }^{2}$
}

\section{RESUMO}

O presente artigo tem por finalidade analisar a relação da Educação Ambiental e a Educação Infantil, trazendo uma breve apresentação histórica do tema abordado, além de discutir as leis que regem a educação ambiental no país, com base no antigo referencial curricular nacional (no eixo natureza e sociedade), na Base Nacional Comum Curricular e nos conceitos e princípios da educação ambiental. São abordadas nesta pesquisa algumas dificuldades apresentadas pelos professores, através de questionário realizado, como também algumas sugestões de propostas para incentivos do governo, visando à qualificação dos docentes na área ambiental para assim gerar mais abertura para a construção de uma consciência ambiental em que os alunos comecem a desenvolver e realizar atitudes sustentáveis dentro e fora da escola.

Palavras-chave: Educação ambiental. Educação infantil. Consciência ambiental.

Data de submissão: 18/03/2021

Data de aprovação: 29/04/2021

\begin{abstract}
The purpose of this article is to analyze the relationship between Environmental Education and Early Childhood Education, bringing a brief historical presentation of the topic addressed, in addition to discussing the laws that govern environmental education in the country, based on the old national curriculum framework (in the nature axis) and society), in the Common National Curricular Base and in the concepts and principles of environmental education. In this research, some difficulties presented by the teachers are addressed, through a questionnaire, as well as some suggestions for proposals for government incentives, aiming at the qualification of the teachers in the environmental area, thus generating more openness for the construction of an environmental awareness in which the students start to develop and carry out sustainable attitudes inside and outside the school.
\end{abstract}

Keywords: Environmental education. Child education. Environmental awareness.

\footnotetext{
${ }^{1}$ Graduanda do Curso de Bacharelado em Pedagogia da Faculdade Metropolitana da Grande Recife.

E-mail: rafaelarocha_nascimento@hotmail.com

2 Professora orientadora do Curso de Bacharelado em Pedagogia da FMGR.

E-mail: silvinharca@hotmail.com
} 


\section{INTRODUÇÃO}

Ao longo do curso de Pedagogia é possível vivenciar diversas situações de ausência de cuidado com o meio ambiente em instituições de ensino, tanto na rede pública como na rede privada. Neste percurso foi observada a necessidade de uma educação ambiental mais presente no cotidiano escolar, principalmente na educação infantil.

Para Naná Mininni (2001), a educação ambiental deve proporcionar às pessoas uma compreensão crítica e global do ambiente. Esclarecer valores e desenvolver atitudes que thes permitam adotar uma posição consciente e participativa dos recursos naturais para a melhoria da qualidade de vida e a eliminação da pobreza extrema e do consumismo desenfreado.

As questões ambientais estão cada vez mais presentes no dia a dia da sociedade. Desta forma, a educação ambiental é fundamental em todas as etapas da educação, especialmente na educação infantil, já que é neste momento que as crianças começam a relacionar-se com a ideia de sociedade e aprende os valores que servirão como base para a vida.

O que mais chamou a atenção foi a falta de informação dos alunos das séries mais avançadas. Este foi o ponto de partida para abordar o presente tema, considerado de extrema necessidade dentro da área da educação, pois buscamos formar indivíduos responsáveis e preocupados com os problemas ambientais e com a preservação dos recursos naturais.

São abordados alguns autores como Moacir Gadotti (2000), Genebaldo Dias (2004) e Heloisa Penteado (2010), que defendem a educação ambiental como disciplina que deve estar presente no cotidiano escolar.

\section{FUNDAMENTAÇÃO TEÓRICA}

Ao pensar em educação ambiental na pré-escola, devemos levar em consideração vários aspectos importantes, como por exemplo, a ausência dessa disciplina no contexto da educação infantil e a falta de formação para os professores nesta área.

A Lei de Diretrizes e Bases da Educação Nacional (LDB - 9394/96), em seu artigo 29, garante que a finalidade da educação infantil é de desenvolver na criança seus elementos físico, psicológico, intelectual e social.

A educação infantil seguia o referencial curricular nacional para a educação infantil de 1998 até 2019, criado com o objetivo de nortear os educadores sobre os eixos que deveriam ser seguidos para a educação infantil.

Dias (1992) afirma que o despreparo e a falta de informações sobre a educação ambiental faz com que o conceito desta área seja equivocado, priorizando problemas ambientais globais, quando deveriam ser discutidos os seus princípios e seus valores e 
atitudes voltadas para a conservação do meio ambiente. Por isto, destaca em sua obra a importância da educação ambiental escolar para a construção de mudanças de valores e atitudes sustentáveis. Para alcançar esse objetivo deve-se utilizar uma pedagogia crítica e libertadora, como a de Paulo Freire.

Já Penteado (2010) afirma que para se ter uma educação ambiental de qualidade é preciso manter os conhecimentos e experiências de cada professor, para organizar uma nova ação educativa que envolva a educação ambiental em todos os campos de experiência, de modo que haja uma construção de uma "consciência ambiental" por parte dos educandos e educadores. De acordo com Penteado (2010, p. 59) "o desenvolvimento da cidadania e a formação da consciência ambiental têm na escola um local adequado para sua realização através de um ensino ativo e participativo".

Gadotti (2013, p. 79), em sua obra Pedagogia da Terra, trata da ecopedagogia. A seu ver “é uma pedagogia de promoção da aprendizagem" que pretende desenvolver um novo olhar sobre a educação.

Neste sentido, a ecopedadogia busca promover a aprendizagem sustentável, não apenas para o bom funcionamento do meio ambiente como também buscar fazer com que os indivíduos formem pensamentos críticos sobre a convivência em sociedade no cotidiano dentro e fora da escola.

A educação ambiental acredita em um processo libertador, em uma sociedade mais justa, baseada no respeito às várias formas de vida que há no planeta. Como diz Gadotti (2000, p. 12), "Precisamos de uma pedagogia da terra, apropriada para este momento de reconstrução paradigmática apropriada à cultura da sustentabilidade e da paz”.

Como podemos perceber com os estudos citados acima, a educação ambiental é de grande importância para o desenvolvimento de cidadãos críticos, levando os indivíduos a refletirem suas práticas no cotidiano de forma sustentável.

\section{BREVE HISTÓRIA DA EDUCAÇÃO AMBIENTAL}

Os problemas ambientais provocados pelos seres humanos decorrem do uso indevido do meio ambiente na obtenção dos recursos necessários à produção dos bens e serviços que eles precisam. Com uma boa base de conhecimento sobre o meio ambiente é possível modificar esse quadro de devastação dos recursos naturais.

$\mathrm{Na}$ década de 50 as consequências dos desequilíbrios ambientais começam a ficar em evidência em episódios como a contaminação do ar, pelas fábricas, em Londres e Nova York; os casos de intoxicação por mercúrio em Minamata e Niigata, no Japão; a morte de aves pelo 
efeito DDT e, principalmente, a bomba atômica de Hiroshima. Os testes nucleares no oceano pacífico começaram a ganhar notoriedade e a serem percebidos como problemas ambientais importantes, primeiro pelas comunidades científicas e depois por parte da população dos países afetados. Já no Brasil, a educação ambiental começa a ser discutida a partir dos anos 60. O ambientalismo se fortaleceu ao aliar-se aos diferentes movimentos sociais deste período.

O primeiro passo que instigou a preocupação com a Educação Ambiental foi resultante de um livro de caráter literário chamado "Primavera Silenciosa", de Rachel Carson, em 1962. O livro alerta sobre os efeitos danosos de inúmeras ações humanas relativas ao meio ambiente.

Em 1968 surge o primeiro registro representativo da educação ambiental que ocorreu na academia de Lincei em Roma, composto por cientistas de vários países e que tinha o objetivo de discutir e propor soluções aos problemas ambientais que surgiram com o crescimento da população mundial.

Já em 1972 houve a conferência de Estocolmo, na Suécia, com a participação de 113 países. Esta conferência é considerada um marco histórico internacional, decisivo no despontar de políticas de gerenciamento ambiental, chamando a atenção do mundo para os problemas ambientais. A partir dela foi instituído o dia internacional do meio ambiente (5 de junho).

O marco seguinte foi em 1975, quando se deu o encontro internacional de educação ambiental de Belgrado. Nesse encontro foram formulados os princípios e orientações para o Programa Internacional de Educação Ambiental (PIEA). Neste mesmo encontro foi elaborada a Carta de Belgrado, que veio a ser um dos mais importantes documentos sobre a questão ambiental e que trata, sobre uma nova ética global, de formas de desenvolvimento que beneficiem toda a humanidade.

A conferência de Tbilisi, considerada a primeira conferência intergovernamental sobre educação ambiental ocorreu no ano de 1977, organizada pela UNESCO, em cooperação com a PNUMA. Este encontro é considerado referência internacional para o desenvolvimento da educação ambiental. Um dos pontos discutidos foi o pressuposto da educação como forma de contribuir para a resolução de problemas ambientais. A conferência de Tbilise estabelece que a EA deve ser tratada como dinâmica, interativa, transformadora, participativa, abrangente e permanente. Nesta mesma ocasião foram traçados os objetivos a as estratégias a serem adotadas por todos os países, no que se refere à educação ambiental.

Em junho de 1992, no Rio de Janeiro, foi realizada a Conferência das Nações Unidas 
sobre meio ambiente e desenvolvimento (Rio-92), em que foi estabelecida uma proposta de ação para os próximos anos, denominada agenda 21. Este documento procurou assegurar o acesso universal da EA em todos os níveis da educação básica.

\section{CONCEITOS E PRINCÍPIOS DA EDUCAÇÃO AMBIENTAL}

A EA é um conceito ainda novo, que gera muitas discussões, embora seja uma das exigências educacionais da modernidade. Essa é uma forma ampla de educação, que se propõe a atingir a todos, através de um processo pedagógico participativo permanente.

A EA não é algo que está simplesmente na moda. Ela possui funções e papéis duradouros e bem definidos, relacionados com o presente e o futuro de nosso planeta, sem se esquecer de mencionar os fatos passados que nos servem de lição.

Na conferência de Tbilisi, foi criado o conceito da educação ambiental:

É um processo contínuo no qual os indivíduos e a comunidade tomam consciência de seu ambiente e adquirem o conhecimento, os valores, as habilidades, as experiências e a determinação que os tornem aptos a agirindividual e coletivamente - e resolver os problemas ambientais presentes e futuros. (UNESCO, 1977).

A concepção de meio ambiente na conferência de Tblilisi assumiu uma maior amplitude, passando a conceber, além dos fatores físicos e biológicos, também outros fatores como o social, político, técnico, ético, cultural e econômico, fornecendo assim à educação ambiental novos horizontes de trabalho que levaram à elaboração de propostas mais globais e eficazes, contidas nos princípios da educação ambiental, advinda desta conferência:

1) Considerar o ambiente em sua totalidade - natural, artificial, tecnológico e social (econômico, politico, histórico-cultural, ético e estético);

2) Ser um processo contínuo ao longo da vida, iniciando-se na pré- escola e prosseguindo por todos os estágios seguintes, formais e não formais;

3) Ser interdisciplinar em suas abordagens, utilizando o conteúdo específico de cada disciplina para tornar possível uma perspectiva equilibrada e holística;

4) Examinar as questões ambientais maiores a partir do ponto de vista locais, nacionais, regionais, e internacionais, para que os estudantes recebam informações sobre as condições ambientais em outras áreas geográficas;

5) Focar em questões ambientais potenciais e atuais sem descurar a perspectiva histórica;

6) Promover o valor e a necessidade da cooperação, local, nacional e internacional, na prevenção e soluções de problemas ambientais;

7) Explicitamente considerar os aspectos ambientais em planos para o desenvolvimento e crescimento;

8) Capacitar estudantes a terem um papel no planejamento de suas experiências de aprendizagem e providenciar-lhes oportunidade de tomar decisões e aceitar suas consequências;

9) Relacionar, para todas as idades, sensibilidade ambiental, conhecimento, habilidade de solução de problemas e valores, mas com especial ênfase em sensibilidade ambiental para os aprendizes da comunidade em tenra idade;

10) Ajudar aprendizes a descobrirem sintomas e causas reais de problemas 
ambientais;

11) Enfatizar a complexidade dos problemas ambientais, e a necessidade de desenvolver consciência crítica e habilidade de solução de problemas;

12) Utilizar diversos ambientes de aprendizagem e uma ampla coleção de métodos educacionais, para que possa ensinar e aprender sobre o ambiente, com devida atenção em atividade práticas e experiências originas. (UNESCO, 1977).

\section{LEIS QUE REGEM A EDUCAÇÃO AMBIENTAL NO BRASIL E EM PERNAMBUCO}

As leis que tratam sobre o meio ambiente no Brasil estão entre as mais completas e avançadas do mundo. Até meados da década de 1990, a legislação cuidava separadamente dos bens ambientais de forma não relacionada. É bem verdade que o trabalho de fiscalização ambiental tem falhas, pelo baixo número de profissionais e pessoas qualificadas para exercerem a função. A legislação é vasta com as garantias dos direitos e deveres, faltando inclusive o seu conhecimento pela população.

A primeira vez que a educação ambiental aparece na legislação de modo integrado é na Lei Federal 6.938, de 1981, que institui a Política Nacional de Meio Ambiente (art. 2, x). Essa lei, posteriormente, é recepcionada pela Constituição Federal de 1988, no capítulo VI, dedicado ao meio ambiente.

De acordo com a Constituição Federal, Art. 225, caput, todos temos direito ao meio ambiente ecologicamente equilibrado. É um bem de uso comum e essencial à boa qualidade de vida. Assim, o poder público e a coletividade têm o dever de defendê-lo e preservá-lo para esta e futuras gerações. Para assegurar a efetividade desse direito, incumbe ao poder público, entre outras providências, promover a educação ambiental em todos os níveis de ensino e a conscientização pública para a preservação do meio ambiente (§ $1^{\circ}$, VI). A educação ambiental tornou- se, então, um dever do estado.

Na constituição do Estado de Pernambuco (1989), no titulo VII, capitulo IV, seção I, artigo 209, é instituído a educação ambiental em todos os níveis de ensino formal, de maneira integrada e multidisciplinar, e como uma necessidade premente.

A nova Lei de Diretrizes e Base (LDB), instituída pela Lei federal No 9394 de 20/12/96, não estabeleceu nenhuma disposição sobre educação ambiental e sequer a cita expressamente. Apenas com muita boa vontade é que se pode atribuir ao legislador alguma intenção de tratar esse tema, ainda que de modo indireto.

\section{A BASE NACIONAL COMUM CURRICULAR (BNCC)}

A Base Nacional Comum Curricular (BNCC) é um documento que estabelece as propostas pedagógicas para a educação, na qual é referência obrigatória para a elaboração dos 
currículos escolares, para as redes de ensino e suas instituições públicas e privadas, fazendo parte do plano educacional nacional desde 1998 prevista na Constituição Federal.

A primeira versão deste documento foi criada em 2014, mas só foi aberta para o público em 2015, em que 45 mil escolas puderam contribuir com suas opiniões. Em 2016 foi criada a segunda versão na qual todo o país pôde opinar. Em 2017 foi realizada a terceira e última versão deste documento, que foi homologado em 22 de dezembro de 2017. A Base Nacional Comum Curricular é dividida em três partes que correspondem às etapas da educação básica: educação infantil, ensino fundamental e ensino médio.

A Base Nacional Comum Curricular (BNCC) divide a educação infantil em três blocos: bebês (zero a 1 ano e 6 meses), crianças bem pequenas ( 1 ano e 7 meses a 3 anos e 11 meses) e crianças pequenas ( 4 anos a 5 anos e 11 meses). Também são estabelecidos na BNCC os seis eixos estruturantes da Educação Infantil: conviver, brincar, participar, explorar, expressar e conhecer. A partir desses eixos são estabelecidos os cincos campos de experiências: Eu, o outro e o nós; Corpo, gestos e movimentos; Traços, sons, cores e formas; Escuta, fala, pensamento e imaginação; Espaço, tempo, quantidades, relações e transformações.

A educação ambiental é um tema que deve ser trabalhado de forma interdisciplinar, para garantir que aconteça a construção de uma consciência sustentável, embora a Base Nacional Comum Curricular (BNCC) não determine o uso da educação ambiental de maneira interdisciplinar. Apenas no campo de experiências "Espaços, tempos, quantidades, relações e transformações", é que a educação ambiental ganha um pequeno espaço para ser trabalhada dentro da sala de aula, pois a base estabelece que: "Educação Infantil precisa promover experiências nas quais as crianças possam fazer observações, manipular objetos, investigar e explorar seu entorno." (BNCC, 2017, p. 42).

\section{O REFERENCIAL CURRICULAR NACIONAL: EIXO NATUREZA E SOCIEDADE}

O Referencial Curricular Nacional para educação infantil foi um documento desenvolvido para nortear os profissionais da educação que atuavam com crianças de zero a seis anos que representou um grande avanço para a época, mas em 2019 entrou em desuso, sendo substituído pela Base Nacional Comum Curricular (BNCC), a qual foi homologada em 20 de dezembro de 2017.

Esse documento abrangia os objetivos, conteúdos e orientações pedagógicas que respeitavam as diferentes culturas do país. Os referencias eram divididos em três volumes. O primeiro volume trazia a introdução do documento onde havia reflexões e conceitos sobre a pré-escola e creches, além de manifestar os fundamentos sobre educação, instituição, criança 
e profissional. O segundo volume tratava da formação pessoal e social e dos processos e etapas do desenvolvimento da identidade e da autonomia de cada indivíduo. O terceiro volume denominado "conhecimento de mundo" era o documento que tratava dos seis eixos de trabalho e orientação para estabelecerem os objetivos dos conhecimentos das crianças. (BRASIL, 1998).

Entre os eixos estabelecidos no referencial curricular nacional, o de natureza e sociedade corresponde ao foco desta pesquisa. Neste eixo foram elaboradas as práticas docentes referentes à educação ambiental. Esse documento estabelecia que as crianças tomassem consciência do mundo de diferentes maneiras e etapas. Por esta razão foram criadas orientações didáticas para inserir a temática em sala de aula, por meio de atividades lúdicas e de maneira interdisciplinar.

Além de orientar os professores sobre a temática e a forma de atuação para inserir a educação ambiental na sala de aula, o documento também questionava a forma de muitas escolas só debaterem o tema em datas comemorativas superficialmente, não atribuindo o que de fato é o meio ambiente.

O volume três ainda organizava os conteúdos em blocos, visando comtemplar todas as dimensões contidas neste eixo, que são: "Organização dos grupos e seu modo de ser, viver e trabalhar"; "Os lugares e suas paisagens"; "Objetos e processos de transformação"; "Os seres vivos"; e "Fenômenos da natureza". Esta organização tinha o objetivo de facilitar a compreensão e o aprendizado dos alunos, assim como na dinâmica dos professores.

\section{METODOLOGIA}

No presente trabalho foi realizada uma análise de como professores da Educação Infantil relacionam a Educação Ambiental e a Educação Infantil. Esta pesquisa foi realizada com seis professores atuantes em instituições públicas, no período de setembro de 2020. Estes professores foram escolhidos, pois todos atuam na educação infantil, sendo que dois deles também atuam em cursos de educação ambiental e um deles atua também em curso de agroecologia.

Esta pesquisa é de caráter qualitativo, uma vez que pretende discutir as questões acerca da educação ambiental, não visando quantificar dados, mas refletir acerca dos dados encontrados dentro de um determinado contexto.

Pautando os estudos na interpretação do mundo real o pesquisador, ao realizar uma pesquisa qualitativa, preocupa-se com o caráter hermenêutico de pesquisar sobre a experiência de vida dos seres humanos, ou seja, a técnica de interpretar e explicar um texto. 
(MOREIRA, 2002, p. 50-51).

As informações constantes neste trabalho foram obtidas por meio de um questionário com perguntas abertas e fechadas sobre o tema abordado e foram respondidas por professores que atuam na educação infantil e trabalham em escolas públicas situadas nos municípios de Jaboatão dos Guararapes, Cabo de Santo Agostinho e Glória do Goitá.

Os sujeitos participantes desta pesquisa, professores da Educação Infantil e atuantes em cursos de educação ambiental e agroecologia, tiveram total liberdade para responder todas as questões, sem direcionamento do pesquisador. Foi apresentado um termo de consentimento para os participantes que quiseram participar, mantendo-os protegidos de qualquer exposição.

\section{RESULTADOS}

Para o presente estudo participaram seis professores, sendo três atuantes na Educação Infantil e três atuantes em cursos especializados em educação ambiental como também na educação infantil. Todos os entrevistados têm formação superior na área da Educação e três deles possuem especialização na área de educação ambiental. Todos os docentes participantes atuam em instituições públicas.

\section{Quadro 01 - Dados gerais dos professores participantes}

\begin{tabular}{|l|l|l|l|l|}
\hline Professores & $\begin{array}{l}\text { Nível de } \\
\text { formação }\end{array}$ & $\begin{array}{c}\text { Tempo que } \\
\text { leciona }\end{array}$ & $\begin{array}{l}\text { Nível de ensino } \\
\text { que trabalha }\end{array}$ & $\begin{array}{c}\text { Localidade de } \\
\text { atuação } \\
\text { (município) }\end{array}$ \\
\hline Professor 01 & Especialização & $\begin{array}{l}\text { Acima de 6 } \\
\text { anos }\end{array}$ & Educação Infantil & $\begin{array}{l}\text { Jaboatão dos } \\
\text { Guararapes }\end{array}$ \\
\hline Professor 02 & Especialização & $\begin{array}{l}\text { Acima de } \\
12 \text { anos }\end{array}$ & $\begin{array}{l}\text { Educação } \\
\text { Infantil }\end{array}$ & $\begin{array}{l}\text { Jaboatão dos } \\
\text { Guararapes }\end{array}$ \\
\hline Professor 03 & Especialização & $\begin{array}{l}\text { Acima de 15 } \\
\text { anos }\end{array}$ & $\begin{array}{l}\text { Educação Infantil } \\
\text { Acima de 15 } \\
\text { anos }\end{array}$ & $\begin{array}{l}\text { Cursoatão dos } \\
\text { Guararapes }\end{array}$ \\
\hline Professor 04 & Especializaçãagia & $\begin{array}{l}\text { Educação } \\
\text { Infantil } \\
\text { Agostinho de Santo }\end{array}$ \\
\hline Professor 05 & Especialização & Acima 20 anos & $\begin{array}{l}\text { Curso pedagogia } \\
\text { ambiental; } \\
\text { Educação } \\
\text { Infantil }\end{array}$ & $\begin{array}{l}\text { Cabo de Santo } \\
\text { Agostinho }\end{array}$ \\
\hline
\end{tabular}




\begin{tabular}{|l|l|l|l|l|}
\hline Professor 06 & Especialização & $\begin{array}{l}\text { Acima de 15 } \\
\text { anos }\end{array}$ & $\begin{array}{l}\text { Curso } \\
\text { agroecologia; } \\
\text { Educação } \\
\text { Infantil }\end{array}$ & Glória do Goitá \\
\hline
\end{tabular}

Fonte: as autoras

Todos os professores entrevistados, como visto no quadro 01, apresentam mais de 06 anos de experiência, o que traz a discussão sobre seus saberes experienciais. Os saberes experienciais são aqueles que se desenvolvem no cotidiano da atividade docente e, por isso, levam em conta as múltiplas interações existentes na prática. Com a experiência de ensino, o professor começa a elaborar sua forma de lidar com as mais diversas situações que ocorrem na sala de aula, e na sua profissão como um todo. Esses saberes, de acordo com Tardif (2002), também são compostos da experiência compartilhada com outros docentes, já que o professor não é um profissional que atua sozinho e isolado. Entendemos, então, que os professores participantes da presente pesquisa já apresentam seus saberes e sua prática consolidada, trazendo reflexões mais elaboradas e concisas sobre as questões educacionais em que eles se envolvem.

Nesse contexto, acreditamos que o professor já está preparado para lidar com situações inesperadas e tem autonomia para tomar as decisões que precisam ser tomadas em sua sala de aula.

Observando o quadro acima, percebemos que três dos entrevistados não atuam diretamente com a educação ambiental e sim com a educação infantil. Já os outros entrevistados trabalham diretamente com a educação ambiental e também atuam com a educação infantil. Consequentemente, os professores que atuam de forma direta nas duas áreas têm mais facilidade de inserir a educação ambiental no cotidiano de suas turmas.

No questionário utilizado para a pesquisa foi perguntado sobre os incentivos do governo para a prática da educação ambiental na escola. Dos seis professores um não respondeu e os outros cinco responderam que não há incentivo por parte do governo para que a educação ambiental aconteça de forma contínua no ambiente escolar. Eles citaram alguns exemplos de incentivos necessários para o bom funcionamento da educação ambiental na escola: formação para os próprios professores na área da educação ambiental, ambientes apropriados para aulas externas onde o aluno possa ter contato com o meio ambiente dentro ou fora da escola, e materiais didáticos voltados para a educação ambiental.

Logo em seguida os professores refletiram acerca da escolha pela área da educação infantil e qual a sua importância. Dos seis docentes, dois afirmaram que não escolheriam a 
área da educação novamente, pois é muito desgastante, mas que a educação é de extrema importância para o desenvolvimento da sociedade. Quatro pesquisados afirmaram que escolheriam a área da educação novamente por inúmeros motivos, como por exemplo, por gostar de lecionar, ver os alunos progredindo e avançando na aprendizagem, por não se ver fazendo outra atividade, por amar o que faz e por afirmar que a pedagogia é uma das profissões mais bonitas que existe. É através da educação escolar que as crianças, além de aprenderem a ler e escrever, aprendem também a se relacionar com o outro, desenvolvendo suas habilidades e tomando consciência do convívio em sociedade.

Ao serem questionados sobre como promover a educação ambiental em sala de aula na educação infantil, os professores listaram algumas sugestões, como podemos ver no quadro 02. Vale ressaltar que os professores puderam destacar mais de uma alternativa.

Quadro 02 - Ações atreladas à promoção da educação ambiental

\begin{tabular}{|l|l|}
\hline \multicolumn{1}{|c|}{ Melhorias } & $\begin{array}{l}\text { Quant. } \\
\text { Professores }\end{array}$ \\
\hline Separação do lixo que produzem dentro da sala de aula & 05 \\
\hline Construir uma horta coletiva & 06 \\
\hline Visitas às reservas naturais & 04 \\
\hline $\begin{array}{l}\text { Utilizar copos, pratos e talheres reutilizáveis, na hora da merenda } \\
\text { escolar }\end{array}$ & 06 \\
\hline Economizar água & 05 \\
\hline Outros & 02 \\
\hline
\end{tabular}

Fonte: as autoras

Os professores que marcaram a opção "outros" citaram o plantio de árvores, aulas ao ar livre, além de incentivos financeiros para a criação de espaços verdes nas escolas. Neste contexto, notamos que, apesar dos professores relatarem que não há incentivo por parte do governo, muito ainda pode ser feito para o envolvimento dos alunos com a educação ambiental sem tirar o foco das outras disciplinas.

De acordo com o Índice de Desenvolvimento Ambiental 2020, o Environmental Performance Index (EPI), o Brasil é o $55^{\circ}$ no ranking da sustentabilidade, porém, os incêndios que ocorreram na Amazônia, Pantanal e a atual pandemia do covid-19 não entraram no índice de 2020. Dessa forma, refletimos sobre a necessidade de uma pedagogia ambiental, mas presente no dia a dia escolar.

Nessa discussão, percebemos que os professores entrevistados têm um olhar bem semelhante quando a questão é a execução da educação ambiental dentro da sala de aula. A educação ambiental é um processo de aprendizagem sobre os recursos naturais e sua 
preservação e, de acordo com Guimarães (2001), esse parecer aponta para uma transformação nas relações do ser humano com a natureza e com a sociedade, que envolve a construção de uma nova ética, novas culturas e novos conhecimentos reflexivos.

Foi perguntado aos docentes quais efeitos podem acarretar em um indivíduo que desde seus primeiros anos escolares teve acesso à educação ambiental. Todos deram respostas positivas, afirmando que se uma pessoa nos seus primeiros anos na escola tiver acesso a uma educação ambiental de qualidade, se tornará um cidadão consciente de suas ações, capaz de resolver problemas ambientais em sua comunidade e suas ações se tornam sustentáveis.

"Os efeitos são positivos, pois as crianças se tornarão adultos conscientes de suas ações.” (Depoimento do professor 02).

"Os alunos serão mais conscientes em relação aos cuidados com o meio ambiente, terão mais cuidado na hora de descartar o lixo e cuidarão melhor da comunidade onde vivem." (Depoimento do professor 04).

"As crianças que tiverem acesso a uma boa educação ambiental durante todo o seu percurso de aprendizagem escola, com toda a certeza serão bem mais hábeis em resolver problemas ambientais e encontrar maneiras sustentáveis de viver em sociedade." (Depoimento do professor 05).

Podemos perceber, a partir dos trechos da fala dos docentes, que uma educação ambiental presente e ativa no cotidiano escolar acarreta mudanças no comportamento dos alunos em longo prazo. Sato (1992) afirma que a "educação ambiental promove a aquisição de habilidades e competências para agir e resolver os problemas ambientais". Portanto, podemos considerar que a educação ambiental é uma garantia de um futuro onde o homem e a natureza viverão em equilíbrio.

Os professores foram questionados se a educação ambiental pode ser trabalhada de forma interdisciplinar. Dos seis entrevistados, dois responderam que não, que a educação ambiental deve ser uma disciplina obrigatória no currículo escolar, pois facilitaria tanto o planejamento como também o acesso a materiais didáticos voltados à educação ambiental. Os outros quatro docentes responderem sim, que a educação ambiental deve ser trabalhada em conjunto com outras disciplinas, visto que dessa forma a temática estaria presente diariamente em sala de aula.

"Não, a educação ambiental deve ser uma disciplina obrigatória, como português e matemática. Desse modo podemos garantir que a temática seja abordada em sala de aula e que ocorra a aprendizagem." (Depoimento do professor 01).

"Sim, a educação ambiental precisar ser abordada de forma interdisciplinar, para garantir que esteja presente no dia-a-dia da turma." (Depoimento do professor 03).

"Com certeza sim, a interdisciplinaridade é essencial para uma educação ambiental de qualidade, uma vez que podemos estabelecer uma relação 
harmônica com a educação ambiental com qualquer outra disciplina." (Depoimento do professor 06).

Diante das respostas dos entrevistados, podemos perceber que mesmo sem uma total concordância na forma de como a educação ambiental pode ser abordada, os docentes afirmam que ela pode ser trabalhada em sala de aula para garantir o desenvolvimento das habilidades e aprendizado. A lei n ${ }^{0}$ 9.795, de 27 de abril de 1999, art. 8, define que a educação ambiental seja inserida nos diferentes níveis e modalidades de ensino de forma interdisciplinar para que ocorra a junção da dimensão ambiental com as demais disciplinas, usando os mesmos instrumentos e metodologia.

Para encerrar o questionário foi perguntado qual a importância da educação ambiental nas creches e pré-escolas. Dos seis, dois afirmaram que é fundamental para o desenvolvimento de uma consciência sustentável para a preservação dos recursos naturais. Um afirmou que é essencial que desde cedo as crianças entendam que o meio ambiente deve ser cuidado e que os seres humanos fazem parte da natureza. Três afirmaram que a educação ambiental desde a creche e pré-escola é de extrema importância para formar cidadãos críticos que tomem consciência dos pequemos e grandes problemas ambientais que enfrentamos e que possam criar soluções para esses problemas. Pequenos hábitos sustentáveis devem estar presentes em seu dia-a-dia, como o simples trabalho de separar e descartar o lixo de forma correta.

\begin{abstract}
"É importante ter uma educação ambiental eficaz desde os anos iniciais e pelos anos subsequentes, não apenas voltada para o aluno, mas também para o educador e todos que fazem parte do sistema educacional, pois qualquer ação realizada pelo homem ao meio ambiente provoca impactos ambientais que pode ser positivo ou negativo. Infelizmente, os impactos em sua maioria são negativos. Com a existência de uma base ambiental, pode acarretar o desaparecimento de vários problemas ambientais, tal como alagamentos, extinção de espécies, mudanças climáticas, poluição e até queimadas, como a que houve no Pantanal que de acordo com as perícias realizadas, uma grande parte dos focos de incêndios foram causados pelas mãos humanas." (Depoimento do professor 05).
\end{abstract}

É possível observar neste depoimento do professor 05 que há pontos positivos em se ter uma educação ambiental ativa na educação infantil, para que ao longo do seu desenvolvimento escolar seja concretizada a consciência ambiental, não só do estudante, mas também dos demais agentes da educação.

\title{
CONSIDERAÇÕES FINAIS
}

Refletir sobre as questões ambientais é muito importante e nos faz perceber que para um bom desempenho da educação ambiental o professor precisar estar sempre buscando 
inovar, já que não existe exigência para a sua abordagem no cotidiano escolar.

Este trabalho apresenta alguns registros de pesquisas já realizadas, como também as respostas do questionário pelos professores, atuantes nas redes de Jaboatão dos Guararapes, Cabo de Santo Agostinho e Glória do Goitá.

De acordo com os docentes que participaram da presente pesquisa, há grandes problemas a serem resolvidos. Alguns desses problemas foram citados na pesquisa, como a falta de formação na área ambiental, espaços impróprios, materiais didáticos escassos ou inexistentes voltados para a educação ambiental. Com isso, podemos observar que a educação ambiental vive uma situação problemática dentro da escola, pois com tantas outras obrigatoriedades, os docentes vão deixando de lado, muitas vezes por falta de informações ou por falta de métodos de adaptar a temática em outras disciplinas, fazendo com que a educação ambiental não seja de fato integrada às outras disciplinas, e sim, que surge como um tema que se dissipa nas atividades desenvolvidas em sala.

O professor é peça fundamental no processo de ensino e aprendizagem e cabe ao Estado fornecer materiais didáticos voltados à educação ambiental para dar apoio ao docente para que ele desenvolva bem suas atividades. Quando falamos em garantias, trazemos as questões observadas nas leis abordadas neste trabalho, que garantem uma educação ambiental presente e de qualidade desde a creche e a pré-escola. Cabe aos governantes realizar os investimentos devidos para a formação de professores ainda mais qualificados para realizar atividades voltadas à sustentabilidade e ao meio ambiente.

Podemos observar que todos os professores que participaram da pesquisa, por estarem no exercício de sua profissão há mais de seis anos, têm certa propriedade para falar sobre o assunto. Entendemos, então, que a educação ambiental é de extrema importância na educação infantil para que se construa uma consciência ambiental forte, garantindo mudanças de comportamento e atitudes que garantam um futuro onde haja equilíbrio entre homem e a natureza.

\section{REFERÊNCIAS}

BRASIL. Lei $\mathbf{n}^{0}$ 9.975, de 27 de abril de 1999. Dispõe sobre a educação ambiental; institui a política nacional de educação ambiental e dá outras providências. Brasília, 1999.

BRASIL. Ministério da Educação e do Desporto. Secretaria de Educação Fundamental. Referencial Curricular Nacional para a Educação Infantil / Ministério da Educação e do Desporto, Secretaria de Educação Fundamental. — Brasília: MEC/SEF, 1998.

BRASIL. Ministério da Educação. Base Nacional Comum Curricular. Brasília, 2017. 
BRASIL. Lei $n^{\circ} 9.394$ de 20 de Dezembro de 1996. Ministério da Educação. Lei de Diretrizes e Bases da Educação Nacional (LDB). Disponível em: http://www.cartadaterrabrasil.com.br/prt/texto-da-carta-da- terra.html $>$. Acesso em: 21 nov. de 2020 .

DIAS, Genebaldo F. Educação ambiental princípios e práticas. São Paulo: Editora Gaia, 2004.

GADOTTI, Moacir. Pedagogia da terra. São Paulo: Ed. Peirópolis, 2000.

GUIMARÃES, Moura. A dimensão ambiental na educação. São Paulo: Editora Papirus, 2001.

PENTEADO, Heloísa D. Meio ambiente e formação de professores. São Paulo: Editora Cortez, 2010.

SATO, Michéle. Educação ambiental. São Carlos-SP: Editora Rima, 2004.

TARDIF, M., Saberes Docentes e Formação Profissional. Petrópolis: Editora Vozes, 2002.

UNESCO. Conferência Intergovernamental sobre Educação Ambiental. Tbilisi, 1977.

\section{APÊNDICE - QUESTIONÁRIO APLICADO}

Dados do entrevistado

Idade:

Há quanto tempo está lecionando?

Formação/graduação:

Qual área de atuação:

Questionário

1. Quais os incentivos do governo para a prática da educação ambiental na escola?

2. Se estivesse no inicio de sua carreira, você escolheria a área da educação infantil novamente? Se sim. Qual a importância que ela tem?

3. Como promover a educação ambiental em sala de aula na educação infantil?

4. Quais os efeitos podem acarretar em um indivíduo, que desde seus primeiros anos escolares teve acesso à educação ambiental? 
5. A educação ambiental pode ser trabalhada de forma interdisciplinar?

6. Qual a importância da educação ambiental nas creches e pré-escolas? 